\title{
Educação do campo e diversidade
}

\section{Ilma Ferreira Machado*}

\section{Resumo}

Neste texto, discute-se que a educação do campo, historicamente desprezada pelas políticas públicas, é uma das dimensóes da diversidade sociocultural de nosso país que não pode mais ser negada. Os programas emergenciais e as políticas compensatórias de outrora, pensadas por agentes externos, centradas no aspecto econômico-produtivo e referenciadas em um padrão de cultura urbana, retratam a perspectiva de tratamento utilitarista e discriminatório dado ao campo. Essas políticas tentaram, dessa forma, silenciar a diversidade sociocultural do campo e a potencialidade criadora de seus sujeitos. Contra essa prática, emergem os movimentos sociais, procurando evidenciar a importância do protagonismo e da autonomia dos sujeitos do campo na construção de projetos político-sociais e pedagógicos que contemplem as especificidades desse contexto, possibilitando articular, em uma dimensão de totalidade, saber local e saber universal e, ao mesmo tempo, buscando superar a polarização campo-cidade.

Palavras-chave: Educação rural. Diversidade cultural.

* Doutora em Educação pela Unicamp. Professora do Programa de Pós-Graduação em Educação, Universidade do Estado de Mato Grosso, Campus de Cáceres. Profa. Adjunta da Universidade do Estado de Mato Grosso, atuante no curso de Pedagogia e no Programa de Pós-Graduação em Educação; desenvolve pesquisa na área de Educação do Campo, Educação e Trabalho, e Organização do Trabalho Pedagógico. 
Todos iguais... Tão desiguais!

Há palavras que nunca são ditas Há muitas vozes repetindo a mesma frase:

Ninguém $=$ ninguém Me espanta que tanta gente minta (descaradamente) a mesma mentira

São todos iguais

E tão desiguais

uns mais iguais que os outros...

Humberto Gessinger

Nos últimos tempos, temos presenciado no Brasil inúmeras discussóes sobre a diversidade aliada à luta pela ampliação das políticas de inclusão social. Apesar dos intensos debates e dos avanços obtidos, esta é uma discussão ainda polêmica. Assim, mais do que cerrar posiçáo sobre esse assunto, gostaria de trazer à tona algumas questóes que me inquietam, externando meu ponto de vista a partir das categorias de análise que elegi.

A polissemia de conceitos aponta para diferentes visóes sobre a diversidade, as quais conduzem a diferentes práticas. O discurso liberal aborda a diversidade como afirmaçáo da desigualdade e discriminação, pois, ao admitir a diferença, o faz em uma condiçâo na qual o diferente é visto como sinônimo de "inferior" e "menos capaz", a quem corresponderia, portanto, menos direitos e menos investimentos ou apenas o suficiente para que se produza uma distribuição "equitativa" dos bens culturais e financeiros, evitando-se, dessa forma, um desequilíbrio nas relaçóes sociais, que poderia colocar em risco a "harmonia" social. Outra corrente forte de pensamento - quase senso comum - cingiu um conceito de diversidade como aceitação (tácita) das diferenças entre as pessoas e contextos, em um apelo, quase piegas, à necessidade de respeito e solidariedade ao próximo. Essa segunda perspectiva, embora se contraponha à primeira, é um tanto limitada, uma vez que exclui a possibilidade de análise em uma dimensão política e de conjunto, ocultando os conflitos decorrentes do enfrentamento das diversidades. Algumas vezes, essa situação contribui para a configuração 
de uma pseudocompreensão da diversidade, fazendo com que as pessoas, veladamente, defendam uma única forma de ser e agir, coerente com seu modo de vida - dado como o mais correto.

Nesse debate, sobram, também, alguns questionamentos e confusóes sobre em que consiste a diversidade e como interpretá-la.

Como entender a diversidade num plano social que coloca a igualdade para todos como um princípio basilar da sociedade dita democrática?

Como entender a igualdade num contexto em que todos são iguais, mas, muitas vezes, "uns são mais iguais que os outros" (como apregoa o grupo Engenheiros do Hawaii)? Essa situação caracteriza uma igualdade falseada e ilusória.

E, se todos são iguais, como admitir a existência da diferença e a diversidade?

É necessário considerar que, embora todas as pessoas sejam membros de uma mesma sociedade, portanto, teoricamente, portadoras dos mesmos direitos, há especificidades entre elas que precisam ser observadas para que de fato se caracterize o tratamento igualitário, superando-se os limites físicos, culturais ou econômicos que se interpóem a elas e que as colocam à margem ou as excluem do processo de aquisição dos bens culturais e econômicos da sociedade.

Talvez aqui caiba fazer uma associação com a análise estabelecida por Luckács (1970) em relação ao particular e ao universal, quando afirma que o particular não é, em uma visão direta e estreita, apenas uma parte ou um pedaço do universal, pois tanto o universal contém elementos e fragmentos do particular, quanto o contrário é verdadeiro. Há, portanto, entre universal e particular uma relação dialética de interpenetração de fatores, porém, o universal configura-se como uma rica manifestação de fatores multidimensionais de uma dada realidade.

Isto posto, é possível afirmar que não há antagonismo entre diversidade e igualdade, e sim algumas contradições que precisam ser exploradas no sentido de redimensionar a visão sobre esse tema. E é com base nesse entendimento, inicialmente explicitado, que abordo, a seguir, sobre a educação do campo. 


\section{Um campo de diversidades}

A partir de 2003, a educação do campo passa a integrar a Secretaria de Alfabetização e Diversidade (Secad), vinculada ao Ministério da Educação, com a constituição de uma coordenadoria responsável pela articulação das demandas educacionais do campo na esfera do governo federal, com desdobramentos para as esferas estaduais e municipais.

Mas por que considerar a educação do campo como uma dimensão da diversidade sociocultural e econômica de nosso país?

Como forma de tentar "responder" a essa indagação, apresento alguns dados do Ministério da Educação (MEC) e do Instituto Nacional de Pesquisas Educacionais (INEP) (BRASIL, 2006) dando conta de que:

- de acordo com o PNAD/IBGE de 2004, 29\% da população adulta analfabeta vive no campo, e 10\%, na cidade; na Regiáo Nordeste, este índice é de 37,7\%, enquanto na Região Sul é de 10,4\%;

- de acordo com o censo dos profissionais do magistério da Educação Básica, realizado em 2003, existem 354.316 educadores do campo, o que representa $15 \%$ dos educadores em exercício em nosso país e são, em sua maioria, os menos remunerados e menos qualificados;

- os educadores do campo, atuantes nos anos iniciais do Ensino Fundamental, recebem, em média, $\mathrm{R} \$ 452,00$, ao passo que, na cidade, a média salarial para essa mesma categoria é de $\mathrm{R} \$ 766,00$ (que também, é baixa);

- apenas $21 \%$ dos professores das escolas do campo possuem formação superior, ao passo que, na cidade, esse índice é de 56\%; $72 \%$ das crianças do campo estão em atraso escolar; na cidade, esse percentual é de 50\%;

- as escolas do campo funcionam em prédios precários e, muitas vezes, improvisados; as escolas multisseriadas e unidocentes, além da precariedade da estrutura física, enfrentam a sobrecarga de trabalho e a alta rotatividade dos professores;

- são raras as escolas que possuem biblioteca e laboratórios, e o transporte escolar, em grande parte delas, é inadequado.

Com base nestes e em outros dados, podemos constatar que há um desprezo histórico com a educação do campo no Brasil. Apesar das 
características marcadamente agrárias de nosso país, ela surge tardiamente e não institucionalizada pelo Estado (BRASIL, 2006). Dos anos 1930 aos anos 1960, a educação do campo constou de políticas compensatórias e programas emergenciais (CALAZANS, 1993), descontextualizados e descontínuos feitos para a população do campo, sem a sua participação e opinião. Nessa prática, estava implícito o predomínio de uma visão urbana de mundo e o princípio da negação do campo como espaço de vida, assim como a previsão do fim do campo. No entanto, tal previsão não se confirmou, porque, conforme dados da Pesquisa Nacional por Amostra de Domicílios (PNAD)/ Instituto Brasileiro de Geografia e Estatística (IBGE), de 2004, 17\% da população brasileira - correspondendo a 30,8 milhóes de pessoas - vive no campo, praticando basicamente a agricultura familiar. Em comparação com a década de 80 , que contava com $32 \%$ da população brasileira vivendo no campo, esse índice é baixo, porém, se formos considerar o avanço vertiginoso do processo de industrialização, é um índice considerável e, ao mesmo, desafiador, pelo fato de o Brasil apresentar uma grande concentração de terras e intensos conflitos agrários. Cabe destacar que cerca de $80 \%$ da produção de alimentos de nosso país advém das pequenas propriedades, da agricultura familiar ou camponesa. Esse dado reforça, ainda mais, a importância do campo na constituição socioeconômica de nosso país.

A concepção do campo como sendo apenas um espaço de produção agrícola e a falta de políticas públicas para esse espaço social propiciaram a perpetuação, ao longo dos tempos, do quadro de precariedade das escolas e a marginalização da educação do campo, que geralmente é associada à falta de qualidade e a um "saber menor", menos exigente e rigoroso. Um tipo de educação "suficiente", nessa concepção, para atender os "matutos", cujo meio social lhes cobra pouco mais que o domínio das primeiras letras, mesmo que, hoje, a tecnologia já se faça presente no campo e que a interface campo-cidade seja uma realidade.

O final da década de 1970 marca o começo da reação dos movimentos sociais contra a situação de marginalização e exploração dos trabalhadores brasileiros, enfim, a luta pela democratização de nossa sociedade. Os anos 1980 foram de intensa movimentação política pelo fim da ditadura militar, pelo direito ao voto e pela escolha dos dirigentes políticos do País, pela estabilidade no emprego e melhoria das condiçóes de trabalho, pela democratizaçáo de acesso e melhoria da escola pública. Nesse processo, 
destaca-se a promulgação da Constituição Brasileira, em 1988, e a aprovação da nova Lei de Diretrizes e Bases da Educação Nacional, em 1996; os movimentos sociais do campo retomam suas lutas, deflagrando diversos movimentos contestatórios e reivindicativos país afora, tendo como mote a reforma agrária.

Em 1988, é constituída a Articulação Nacional por uma Educação Básica do Campo, com a participação do Movimento dos Trabalhadores sem Terra (MST), da Organização das Nações Unidas para a Educação a Ciência e a Cultura (Unesco), do Fundo das Naçóes Unidas para a Infância (Unicef), universidades e outras entidades populares, que teve o importante papel de fomentar discussóes e de sistematizar propostas de políticas educacionais para o campo. E, em 2002, por força de toda essa mobilização, é aprovada pelo Conselho Nacional de Educação/Câmara de Educação Básica a Resolução no 01, ("Diretrizes nacionais por uma educação básica nas escolas do campo"), caracterizando-se como um forte instrumento de fortalecimento da educaçáo do campo.

De acordo com essa Resolução, constituem pressupostos básicos da educação do campo: respeito à identidade e diversidade sociocultural, desconstrução da visão do sujeito do campo como "caipira" e "atrasado", articulação entre educação e desenvolvimento sustentável, autonomia e protagonismo dos sujeitos do campo, educação como princípio de formação humana e de inclusão social. Nessa linha, a educação é entendida como um processo amplo, permanente e não restrito ao ensino. Para constituirse verdadeiramente como um processo de formaçáo humana, na acepçáo ditada por Marx e Engels (1978), cabe pensar a educação em uma perspectiva integral, que alie as dimensóes técnicas, culturais e políticas. Mas como trabalhar essa diversidade e assegurar que ela seja observada nos processos e práticas das escolas do campo, que abrange camponeses, ribeirinhos, quilombolas, entre outros, com culturas e organizaçôes sociais e políticas diferenciadas? Penso que o enfrentamento dessa questão envolve estratégias tais como:

- rechaçar a mera transposição de propostas pedagógicas das escolas urbanas para as escolas do campo e, o que talvez seja mais grave, o aligeiramento ou superficialização do conhecimento veiculado por essas propostas, o que penaliza duplamente as crianças e os jovens do campo. Coloca-se como primordial, entâo, a construção 
de propostas pedagógicas, que valorizem os diversos saberes dos sujeitos que vivem no campo, contudo, sem secundarizar o conhecimento científico e a cultura universal, que são fatores essenciais para a ampla formação dos sujeitos. Nesse processo, é fundamental incorporar a agroecologia como um novo conceito de vida, implicando não apenas uma produção mais saudável, livre de agrotóxicos, como também, a discussão sobre soberania alimentar e manejo sustentável do solo e dos recursos naturais. Tais questôes não se colocam apenas no plano técnico, mas fundamentalmente no plano das decisóes políticas sobre o tipo de sociedade que queremos construir e sobre tipo de relaçóes humanas que devem pautá-la;

organizar propostas pedagógicas que integrem desenvolvimento humano e tecnológico, que procurem superar a dicotomia urbanorural, o que pressupóe uma mudança curricular e na organização do trabalho pedagógico, prevendo-se a diversificação dos espaços de aprendizagem e a realização da avaliação formativa. A aula como um dos espaços pedagógicos necessita ser redimensionada, suprimindo-se as tarefas meramente técnicas e rotineiras, que parecem ter como única finalidade "preencher o tempo" ou manter as crianças ocupadas, e substituindo-as por tarefas e atividades consistentemente programadas e com finalidades claramente evidenciadas, que correspondam ao projeto de formação integral do sujeito;

conceber teoria e prática como dimensóes inseparáveis do processo pedagógico; a teoria é imprescindível para o entendimento das questóes de nossa atualidade, que não podem ficar fora da organização curricular da escola do campo, assim como a articulação entre educação e trabalho, uma vez que é pelo trabalho, e pelas relações sociais que dele se depreendem, que os homens formulam suas concepçóes de vida, criam seus instrumentos de sobrevivência e desenvolvimento, constituem sua cultura, enfim, hominizam-se (LUKÁCS, 1981). O conhecimento está intimamente ligado às tramas e relaçóes do mundo do trabalho (PISTRAK, 2002), não podendo, portanto, ser abordado alheio a esse processo, sob pena de se revelar demasiadamente fragmentado e superficializado. $\mathrm{O}$ ensino deve abranger tanto a formação intelectual quanto a 
tecnológica e ser coerente com o método dialético de interpretação da realidade. Nessa perspectiva, conforme Machado (2003), as atividades escolares consistirão no estudo do trabalho humano e na participação dos estudantes nas diversas formas de trabalho; o trabalho humano se apresenta, assim, como um elemento integrante da relação escola-realidade, e objetivo da escola não é apenas instruir, mas sim transformar o conhecimento em concepçóes ativas, implicando o domínio das ciências, ou seja, do método científico, o que pode ser essencialmente atingido via trabalho (PISTRAK, 2002);

- priorizar a gestão democrática como forma de eliminar a centralização das decisóes escolares nas secretarias de educação ou assessorias pedagógicas dos municípios ou dos Estados. A gestão democrática constitui mecanismo valiosíssimo de participação e de construção da autonomia nas escolas do campo, uma vez que coloca para estudantes, educadores e direção a possibilidade de fazer escolhas a partir de um pôr teleológico, ou seja, de discutir e definir o que se entende ser melhor e mais compatível com o projeto educativo e com as condiçóes de funcionamento da escola e, principalmente, a possibilidade de exercício de trabalho coletivo, no qual as decisóes a serem tomadas refletirão sempre, e necessariamente, o pensamento de várias pessoas, e náo de uma apenas.

Algumas mudanças têm que ser incorporadas ao contexto social em que se situam as escolas do campo para que as açóes escolares tenham ressonância e sejam validadas pelos grupos sociais no sentido da interiorização de novos valores e práticas. É nesse espaço educativo maior que as diversidades se manifestam e são, muitas vezes, sufocadas. Cabe, pois, à escola alimentar esse debate, tendo, porém, o cuidado de respeitar as concepçóes de mundo e os tempos de aprendizado das pessoas, estabelecendo o diálogo, justamente, a partir das diferenças de concepçóes e dos dissensos, nem sempre fáceis de serem encarados pelos sujeitos.

Ao abordar a temática da diversidade, procuro ficar atenta às críticas de alguns teóricos, a exemplo de Duarte (2008), quanto à negatividade implícita nas "pedagogias relativistas", as quais, em nome da valorização do saber popular, redundariam no relativismo cultural que, ao invés de produzir 
ganhos significativos para os estudantes, filhos de trabalhadores, poderia acarretar enormes perdas e até mesmo o esvaziamento do currículo escolar.

Náo é difícil perceber que o relativismo cultural incide diretamente sobre o currículo escolar, acarretando, no limite, sua total fragmentação e até mesmo sua insolvência. Como definir conteúdos que devam ser ensinados a todas as crianças se o critério de relevância ou até mesmo de veracidade dos conhecimentos é a cultura específica à qual pertence o indivíduo? Como definir-se um currículo comum a todos se não existe uma cultura comum a todos? Se existem milhares de culturas particulares, existirão milhares de currículos, ou o currículo escolar é dissolvido e em seu lugar é colocado um suposto diálogo entre as culturas nas quais estáo inseridos os alunos? $\mathrm{E}$ o que define qual é a cultura de cada aluno: etnia, classe social, gênero, idade, local onde mora, os meios de comunicaçâo, os estilos musicais, as religióes, as atividades de lazer, o esporte preferido? $\mathrm{O}$ relativismo, tanto em seu aspecto epistemológico como no cultural, leva a uma ausência de referências para a definição do que ensinar na escola às novas geraçôes. (DUARTE, 2008, p. 4).

Parece pertinente esclarecer que entendo que não há como subtrair a discussão sobre diversidade da questão político-social mais ampla, bem como das relaçóes entre capital e trabalho, que engendram uma multiplicidade de fatores, conformando a dinâmica das relaçóes estabelecidas entre os sujeitos em diversos espaços, do familiar e mais privado ao social e mais coletivo.

Nesse sentido, a diversidade deve ser concebida como luta pelo direito de ser e como movimento de resistência às tentativas de homogeneização $e$ enquadramento sociocultural de sujeitos tão diferentes, do ponto de vista da origem familiar e do capital cultural (BOURDIEU, 1998), e do ponto de vista econômico, que situa os sujeitos em determinada classe social, conforme seu capital econômico. As relaçóes entre capital cultural e poder econômico foram exaustivamente apontadas por Bourdieu, que procurou evidenciar que aqueles que detêm menor poder econômico são detentores, também, de menor capital cultural, e que esta é uma desigualdade que a escola tende a reforçar, quando deveria contribuir para minimizar. 
Se a ação indireta da escola (produtora dessa disposição geral diante de todo tipo de bem cultural que define a atitude "culta") é determinante, a ação direta, sob a forma do ensino artístico ou dos diferentes tipos de incitação à prática (visitas organizadas, etc.), permanece fraca: deixando de dar a todos, através de uma educação metódica, aquilo que alguns devem ao seu meio familiar, a escola sanciona, portanto, aquelas desigualdades que somente ela poderia reduzir. Com efeito, somente uma instituição cuja função específica fosse transmitir ao maior número possível de pessoas, pelo aprendizado e pelo exercício, as atitudes e as aptidóes que fazem o homem "culto" poderia compensar (pelo menos parcialmente) as desvantagens daqueles que náo encontram em seu meio familiar a incitação à prática cultural. (BOURDIEU, 1998, p. 61).

Com base nos antecedentes históricos da educação do campo e nas ideias formuladas por Bourdieu (1998) e Freitas (1995), penso que não é exagero afirmar que, no campo, há uma maior discrepância de capital cultural em relaçáo ao contexto urbano, uma vez que os campesinos tradicionalmente foram alijados do acesso aos bens culturais da humanidade, constituído pela cultura erudita, e ao conhecimento sistematizado veiculado pela escola. Tais fatores contribuíram para promover a formação de um baixo capital cultural. Contudo, isso não significa desacreditar os campesinos e considerálos menos capazes ou desprovidos de sabedoria e de cultura. Significa, sim, que há uma desigualdade no ponto de partida que precisa ser reconhecida. Nesse sentido, cabe registrar essas diferenças e desigualdades, e visualizar formas de superá-las. A diversidade se coloca, então, no contexto da discussão sobre as desigualdade e marginalização daqueles que, historicamente, foram excluídos da sociedade.

Ao invés de olharmos para os sujeitos desses contextos e para os movimentos sociais e afirmativos como algo exótico ou bizarro, talvez devêssemos tomá-los como possibilidades de mudança e melhoria social, de que tanto falamos e defendemos. Isso porque, no processo de reafirmação de suas singularidades (e das diversidades), é possível iniciarmos um movimento de contraposição ao domínio eurocentrista estabelecido até então, no sentido 
de fazer chegar a esses excluídos os direitos que lhes foram negados pela ausência de políticas públicas que contemplassem suas especificidades. Falar em especificidades é discutir, de certa forma, o espaço geopolítico, falar da reterritorializaçáo do poder e do conhecimento a partir do local, do regional ou da realidade mais próxima dos sujeitos.

No processo de globalização, entendido como uma nova forma de reordenamento do capital mundial (IANNI, 1997), estabelece-se uma relaçáo contraditória entre local e universal, pois, ao mesmo tempo em que se observa a transnacionalização do capital e da divisão do trabalho, com a defesa dos fins das fronteiras entre os países e com o enfraquecimento do Estado-naçáo, registra-se, também, um forte estímulo à constituição das forças locais. Do ponto de vista do capital, esse estímulo se constitui uma estratégia de escamotear o processo de concentraçáo de capital e de agregar forças dos "pequenos", mesmo porque não é possível conter todas as iniciativas brotadas nesse contexto. Apesar dessas marcantes contradiçóes, o fortalecimento da cultura e da economia local pode revelar-se um poderoso instrumento de mudanças e de afirmação de uma nova ordem social. Contudo, isso não pode se dar com base em uma atitude romântica e ingênua de pensar que tudo se esgota/resolve em âmbito local, perdendo-se a dimensão do universal, do global.

É natural, porém, que a eleição do lugar ou da região e seus traços significativos como portadores de sentido e, portanto, como objetos de pesquisa tenham que ser inevitavelmente uma definição política. Os que estão nos grandes centros urbanos e de pesquisa, que sempre foram regiôes mais assistidas, notadamente no que concerne aos recursos, sempre vão relutar em fazer esse reconhecimento. Afinal, a regiāo é objeto de luta, também, entre os cientistas, como pontua o sociólogo francês Pierre Bourdieu. O discurso sobre a região faz parte das classificaçóes ou das "[...] lutas pelo monopólio de fazer ver e fazer crer, de dar a conhecer e de fazer reconhecer, de impor a definição legítima das divisôes do mundo social e, por este meio, de fazer e desfazer os grupos" (PESSOA, 2007, p. 6). 
Portanto, para além das paixóes regionalistas e da incondicional defesa do saber popular, a diversidade deve ser entendida como o reconhecimento histórico, cultural e sociopolítico das diferenças, contra as tentativas de homogeneização de ideias e sujeitos. Nesse sentido, a educação do campo se coloca na perspectiva de direito à vida e à cidadania plena, na perspectiva de aprender a "soletrar a liberdade na cartilha do a, b, c", conforme diz uma das músicas do MST, cantada por Beth Carvalho.

Um dos principais objetivos que estão colocados no âmbito dessa luta é a valorização do campo como um rico espaço social e econômico, como espaço de vida e de manifestação cultural diversa, em contraposição à ideia, bastante difundida no Brasil, do campo como símbolo do atraso e da ignorância. Com base nessa concepção, cabe pensar o campo em uma dimensão coletiva e solidária que propicie o fortalecimento do sentimento identitário entre os povos do campo e destes com a classe trabalhadora, e a constituição de um novo modelo social em que todos os trabalhadores se apropriem dos meios de produção e que estabeleçam entre si relações horizontalizadas e coletivistas, invertendo a lógica da exploração do homem sobre o homem.

É nessa perspectiva que têm se colocado os movimentos sociais no campo, que, embora apresentem questóes pontuais, postulam mudanças macroestruturais, defendendo uma vida digna para todos que vivem no campo e do campo, entendendo que essa luta não tem fronteiras, inclui todos os trabalhadores, englobando, portanto, campo e cidade, que, diferentemente da visão de outrora, expressam relação de complementaridade, uma vez que ambos carregam traços um do outro. Nada disso é tranquilo, livre de conflitos, muito pelo contrário, é prenhe de contradiçóes, tais como as descritas por Ianni (1997) em relação ao processo de globalização.

Globalização rima com integração e homogeneização, da mesma forma que com diferenciação e fragmentação. A sociedade global está sendo tecida por relaçóes, processos e estruturas de dominação e apropriação, integração e antagonismo, soberania e hegemonia. Trata-se de uma configuração histórica problemática, atravessada pelo desenvolvimento desigual, combinado e contraditório. As mesmas relaçóes e forças que promovem a integração 
suscitam o antagonismo, já que elas sempre deparam diversidades, alteridades, desigualdades, tensōes e contradiçóes [...] A mesma globalização alimenta a diversidade de perspectivas, a multiplicidade dos modos de ser, a convergência e a divergência, a integração e a diferenciação; com a ressalva fundamental de que todas as peculiaridades são levadas a recriar-se no espelho desse horizonte, no contraponto das relaçóes, processos e estruturas que configuram a globalização. (IANNI, 1997, p. 32).

$\mathrm{Na}$ esteira desse movimento de valorização da diversidade, colocase a possibilidade de afirmação de uma educação crítica e emancipatória, bem como de construção de outra forma de escola (VINCENT, 2001) em contraposição à escola fechada em si mesma e excludente. Excludente porque nega as possibilidades de permanência dos sujeitos em seu interior, e porque lhes nega o acesso ao conhecimento científico em sua inteireza e consistência, restando-lhes muitas vezes alimentar-se das migalhas de conhecimento ditadas pelo livro didático ou pelas apostilas.

A superação desse quadro, além de uma infraestrutura apropriada à escola do campo, exige uma política de formação inicial e continuada coerente com uma concepção de educação crítica, pois é o professor quem, em última instância, implementa os princípios dessa nova forma escola a ser constituída, e é sabido que a formação precária, aliada aos baixos salários, à sobrecarga de trabalho e à alta rotatividade dos professores, contribui para o baixo desempenho dos alunos e até mesmo para afastá-los da escola. Assim, cabe pensar em uma formação profissional que, além das disciplinas clássicas, contemple o estudo e a reflexão sobre a realidade do campo, com suas especificidades sobre época (calendário) de plantio e colheita, atividades das quais as crianças e suas famílias se ocupam. É importante analisar, portanto, as formas de trabalho e as manifestaçóes religiosas e culturais, enfim, as relaçóes sociais que se desdobram nesse contexto e que, em grande medida, repercutem sobre a vida na escola e sobre a educação.

Para mim, a grande contribuição que as discussóes sobre diversidade têm trazido é chamar nossa atenção à pulsante e caleidoscópica realidade do mundo de sujeitos coletivos, com as singularidades que carregam e que os fazem unos e ao mesmo tempo universais, o que nos desafia e instiga a 
criar formas de agir capazes de resguardar essa diversidade, tanto no plano das relaçóes pessoais quanto no plano das relaçóes sociopolíticas e de caráter institucional. E isso significa mexer nos valores, na cultura dos sujeitos e nas relações sociais de trabalho para gestar um novo projeto de sociedade que tenha por princípio a humanização dessas relações, e o fim da exploração e da alienação.

\section{REFERÊNCIAS}

BORDIEU, Pierre. A escola conservadora: as desigualdades frente à escola e à cultura. In: NOGUEIRA, Maria Alice; CATANI, Afrânio M. (Org.). Escritos de educação. Petrópolis: Vozes, 1998.

BRASIL. Conselho Nacional de Educação. Resolução no 01 de 3 de abril de 2002. Câmara de Educação Básica. Institui diretrizes operacionais para a Educação Básica nas escolas do campo. Brasília, 2002.

BRASIL. Ministério da Educação. Instituto Nacional de Pesquisas Educacionais. Panorama da educação do campo. Brasília, 2006.

CALAZANS, Maria J. C. Para compreender a educação do Estado no meio rural - traços de uma trajetória. In: TERRIEN, Jacques; DAMASCENO; Maria N. (Org.). Educação e escola no campo. Campinas: Papirus, 1993. p. 15-42.

DUARTE, Newton. Pela superação do esfacelamento do currículo realizado pelas pedagogias relativistas: texto apresentado no IV Colóquio LusoBrasileiro sobre Questóes Curriculares, realizado na Universidade Federal de Santa Catarina, Florianópolis, setembro de 2008. Mimeografado.

FREITAS, Luiz. C. Crítica da organização do trabalho pedagógico e da didática. Campinas: Papirus, 1995.

IANNI, Octávio. A era do globalismo. 3. ed. Rio de Janeiro: Civilização Brasileira, 1997.

LUKÁCS, George. Introdução a uma estética marxista. 2. ed. Rio de Janeiro: Civilização Brasileira, 1970.

- O trabalho: por uma ontologia do ser social. Alagoas:

Universidade Federal de Alagoas, 1981. 
MACHADO, Ilma F. A organização do trabalho pedagógico em uma escola do MST e a perspectiva de formação omnilateral. 2003.307 f. Tese (Doutorado em Educação) - Faculdade de Educação, Universidade Estadual de Campinas, Campinas.

MARX, Karl; ENGELS, Friedrich. Crítica da educação e do ensino. São Paulo: Moraes, 1978.

PESSOA, Jadir. Lugar e pessoa na cultura popular. In: GRANDO, Beleni S. (Org.). Corpo, educação e cultura: tradiçóes e saberes da cultura matogrossense. Cáceres: Editora Unemat, 2007.

PISTRAK. Moisei. Fundamentos da escola do trabalho. São Paulo:

Expressão Popular, 2002.

VINCENT, Guy. Sobre a história e a teoria da forma escolar. Educação em Revista, Belo Horizonte, n. 33, p. 7-48, jan./jun. 2001. 


\section{Rural education and diversity Educación rural y diversidad}

\section{Abstract}

This text discusses the fact that rural education has been historically neglected by public policy, yet it cannot be denied that it is one of the dimensions of socio-cultural diversity in Brazil. The emergency programs and past compensatory policies developed by foreign agents focused on economic-productive factors and were based on urban standards, indicating the utilitarian and discriminatory treatment given to rural regions. These policies attempt to silence the sociocultural diversity of rural areas and the creative potential of its subjects. Social movements arose in response to these practices in an attempt to reveal the importance of the role and autonomy of rural subjects in the construction of political-social and pedagogical projects that contemplate the specificities of this context, allowing the complete articulation of local and universal knowledge while simultaneously seeking to overcome rural-urban polarization.

Key words: Rural education. Cultural diversity.

\section{Resumen}

Em este texto se discute que la educación rural, historicamente despreciada por las políticas públicas, Es uma de las dimensiones de la diversidad sóciocultural de nuestro país que no puede ser negada. Los programas emergenciales y las políticas compensatorias de antes, pensadas por agentes externos, centradas en el aspecto económico - productivo y teniendo como referencia un padrón de cultura urbana, retratan la perspectiva de tratamiento utilitarista y discriminatorio otorgado al campo. De esa forma, esas políticas tentaron, silenciar la diversidad socio-cultural y la potencialidad creadora de sus sujetos. Contrarios a esa práctica, surgieron los movimientos sociales, con el objetivo de evidenciar el protagonismo e la autonomía de los sujetos de las áreas rurales en la construcción de proyectos políticos y pedagógicos que contemplen las especificidades de ese contexto, posibilitando articular, a partir de una dimensión de totalidad, el saber local y el saber universal y, al mismo y tiempo, buscando superar la polarización entre el campo y la ciudad.

Palabras clave: Educación rural. Diversidad.

\section{Ilma Ferreira Machado}

Universidade do Estado de Mato Grosso - Av. São João S/N

Cavalhada CEP: 78200-000 - Cáceres-MT

Telefone: (65) 3221-0500

URL da Homepage: http://www.unemat.br

E-mail:ilmafm@terra.com.br

Recebido em: $20 / 1 / 2010$

Aprovado em: 20/4/2010 